\title{
What is the most common mammographic appearance of T1a and T1b invasive breast cancer?
}

\author{
Maja Podkrajšek ${ }^{1}$, Janez Žgajnar ${ }^{2}$, Marko Hočevar ${ }^{2}$ \\ ${ }^{1}$ Department of Radiology and ${ }^{2}$ Department of Surgical Oncology, \\ Institute of Oncology Ljubljana, Slovenia
}

Background. Data about the mammographic appearance of breast cancer smaller than $10 \mathrm{~mm}$ are very limited and different authors use different mammographic criteria. The aim of this study was to determine the most common mammographic appearance of small invasive breast cancers (T1a and T1b).

Patients and methods. The study group consisted of 100 women with 102 small (1-10 mm) invasive breast cancers detected on mammography at a single institution in 16 months period. The mammographic appearance of tumours was classified as: mass, mass with associated calcifications, only calcifications or others (asymmetric density and architectural distortion).

Results. The most common mammographic appearance was a mass without calcifications (60/102; 59\%). Additional 12/102 (11\%) tumours had a mammographic appearance of a mass with associated calcifications. Only microcalcifications were detected in 12 (11 \%) and asymmetric density and architectural distortion in 18 breast cancers (18\%). Most (44/60) cancers which presented mammographically as a mass had stellate margins. The proportion of castig type calcifications was higher in women under 50 years.

Conclusions: The most common mammographic finding of small breast cancer is a mass with stellate margins independent of the age of patients. Calcifications with/without mass are more common in woman under 50 years.

Key words: breast cancer; mammographic appearance; microcalcifications, stellate; casting; asymmetric density

\section{Introduction}

Breast cancer is the most common noncutaneous cancer in European women. In Slovenia 1020 new cases and 425 deaths from breast cancer are estimated in 2005. An average Slovenian woman has a lifetime risk of 1 in 16 for developing breast cancer. ${ }^{1}$

Received 13 October 2008

Accepted 5 November 2008

Correspondence to: Prof. Marko Hočevar, MD, PhD, Institute of Oncology Ljubljana, Zaloška 2, SI-1000 Ljubljana, Slovenia. Phone: +386 15879 534; Fax: +386 15879 407; E-mail: mhocevar@onko-i.si
Mammography can identify breast cancers too small to palpate on physical examination. Clinical trials have established that screening with mammography may decrease breast cancer mortality, because breast cancers detected on screening mammography are smaller and more likely not to have spread to regional lymph nodes as compared with breast cancers detected at physical examination. ${ }^{2-4}$ Additionally, since breast cancers detected on screening mammography are smaller, they can be more often treated with breast conservation and with less-toxic systemic therapy. ${ }^{5}$ 
Table 1. Classification of mammographic findings

\begin{tabular}{lc}
\hline 1 & Mass without calcifications: \\
& with stellate margins \\
& round/oval mass \\
\hline 2 & Mass with calcifications \\
\hline $3 \quad$ Only calcifications: \\
casting \\
powdery \\
crushed-stone like \\
\hline $4 \quad$ Others: \\
asymmetric density \\
architectural distorsion
\end{tabular}

If we want to detect with mammography small breast cancers, we have to use the accurate mammographic criteria for early (T1a and T1b) invasive breast cancers. However, there are only a few publications in the literature about the mammographic appearance of breast cancer smaller than 10 $\mathrm{mm} .{ }^{6}$ Additionally, there is unfortunately no standardized approach - different authors use different mammographic criteria for breast cancers smaller than $10 \mathrm{~mm}$.

The aim of this study was to determine the most common mammographic findings of small invasive breast cancers (T1a and $\mathrm{T} 1 b)$.

\section{Patients and methods}

In the 16 months period (from September 2003 to December 2004) 100 consecutive women (aged 36-77 years; mean 59 years) with 102 pathologically proven small (pT1a and $\mathrm{pT} 1 \mathrm{~b}$ ) breast cancers were treated at the Institute of Oncology in Ljubljana, Slovenia. Most of the cancers were nonpalpable (80/102) and detected on screening mammography. Palpable cancers were tumours which were palpable in the same quadrant as histologically proven tumours
Table 2. Distribution of mammographic findings in 102 small breast cancers

\begin{tabular}{|c|c|c|c|}
\hline & & No & $\%$ \\
\hline \multirow[t]{3}{*}{1} & Mass without calcifications & 60 & 59 \\
\hline & stellate & 44 & \\
\hline & round or oval & 16 & \\
\hline \multirow[t]{4}{*}{2} & Mass with calcifications & 12 & 11 \\
\hline & powdery & 1 & \\
\hline & crushed-stone like & 2 & \\
\hline & casting & 9 & \\
\hline \multirow[t]{4}{*}{3} & Only calcifications & 12 & 12 \\
\hline & powdery & 3 & \\
\hline & crushed-stone like & 1 & \\
\hline & casting & 8 & \\
\hline \multirow[t]{4}{*}{4} & Other & 18 & 18 \\
\hline & asymmetric density & 14 & \\
\hline & architectural distortion & 4 & \\
\hline & Total: & 102 & $100 \%$ \\
\hline
\end{tabular}

and which were cytologically proven for cancer (C5) without imaging modality.

Mammographic lesions were classified according to BIRADS: ${ }^{7} 4$ lesions as R2, 28 lesions as R3, 66 as R4 and 4 as R5. Free hand fine needle aspiration biopsy (FNAB) was performed in all 20 patients with palpable tumours. Cytology was positive (C5) in 14/20 patients and non diagnostic (C1) in $6 / 20$. In these six patients, as well as in all other cases $(80 / 102)$ of non palpable tumour, image guided FNAB (58 cases) or core biopsy (28 cases) was performed. In 51 cases biopsy guidance was done by the ultrasound (US) and in 35 by the stereotaxy.

Preoperative diagnosis of breast cancer was established in 67 patients (C5 in 48 cases and B5 in 19 cases) with nonpalpable tumours. Occult lesion localization (40/67 by stereotaxy and $27 / 67$ by US) with $30-60 \mathrm{MBq}$ of $99 \mathrm{~m}$ Tc labeled nanocolloid $\left(\mathrm{Nanocol}{ }^{\circledR}\right.$ ) in $0.2 \mathrm{ml}$ saline was performed on the morning of surgery. Tumourectomy 
Table 3. Distribution of mammographic findings in 28 small breast cancers in women under the age of 50 years

\begin{tabular}{|c|c|c|c|}
\hline & & No & $\%$ \\
\hline \multirow[t]{3}{*}{1} & Mass without calcifications & 11 & 39 \\
\hline & stellate & 10 & \\
\hline & round or oval & 1 & \\
\hline \multirow[t]{4}{*}{2} & Mass with calcifications & 6 & 21,5 \\
\hline & powdery & 0 & \\
\hline & crushed-stone like & 2 & \\
\hline & casting & 4 & \\
\hline \multirow[t]{4}{*}{3} & Only calcifications & 6 & 21,5 \\
\hline & powdery & 2 & \\
\hline & crushed-stone like & 1 & \\
\hline & casting & 3 & \\
\hline \multirow[t]{4}{*}{4} & Other & 5 & 18 \\
\hline & asymmetric density & 4 & \\
\hline & architectural distortion & 1 & \\
\hline & Total: & 28 & $100 \%$ \\
\hline
\end{tabular}

(58/67), quadrantectomy (3/67) or mastectomy $(6 / 67)$ were combined with a sentinel lymph node biopsy (SLNB).

In 31 patients with preoperative $\mathrm{C} 3 / \mathrm{C} 4$ (22 patients) or B2-4 (9 patients) radioguided occult lesion localization (ROLL) and excisional biopsy were performed. ROLL was performed in 26 cases under stereotaxic and in 5 cases under sonographic control. After the histological diagnosis of breast cancer (B5), in the second surgical procedure reexcision of the primary site (22 patients), quadrantectomy (2 patients) or mastectomy (3 patients) and SLNB was performed. In four patients only SLNB was performed because of adequate margins (more than 10 $\mathrm{mm}$ ) after the excisional biopsy.

Two patients with palpable cytologically proven breast cancers (C5) underwent tumourectomy and axillary dissection because preoperative US examination and US guided FNAB of the axillary lymph nodes revealed metastases in lymph nodes. ${ }^{8}$
All mammographic images were reviewed by a single radiologist (PM), who has a special interest and dedication in breast radiology. Mammographic findings were classified according to Table 2, as seen in Table 1. A mass is defined as a lesion seen in two different projections, while a density is observed only in a single projection according to Samardar. ${ }^{9}$

Pathologic characteristics of primary tumours included size, histologic type, grade (according to Bloom, Richardson and Elston), status of axillary lymph nodes, estrogen and progesteron receptors and HER2 status. The histological type of breast cancers was as follows: invasive ductal, invasive lobular, tubular, mucinous, medullary and papillary.

For the statistical analysis descriptive statistical methods were used.

\section{Results}

The mean size of breast cancers was 8.1 $\mathrm{mm}$ (range 4-10 mm; pT1a in 18 and pT1b in84 cases). Histologically 86/102 (84\%) were invasive ductal, 14/102 (14\%) invasive lobular and 2/102 (2\%) invasive tubular cancers. There were 48/102 (47\%) grade I, 41/102 (40\%) grade II and 13/102 (13\%) grade III cancers. The great majority of patients (98/100) had no metastasis in lymph nodes. Estrogen and progesteron receptors were positive in 91 patients, while there were only 8 patients with positive HER2 tumours.

The most frequent mammographic finding was a stellate mass without calcifications, which was seen in 44/102 (43\%) cancers (Table 2). Casting type calcifications were found in 17/102 (17\%) cancers.

There were 28 patients younger than 50 years and Table 3 shows mammographic findings in this group of patients. The most frequent mammographic finding was a stel- 
Table 4. The association between mammographic appearance and histologic type and grade of the tumor

\begin{tabular}{|c|c|c|c|c|c|c|c|}
\hline & & IDC & ILC & ITC & $\begin{array}{r}\text { Gradus } \\
\text { III }\end{array}$ & $\begin{array}{r}\text { Gradus } \\
\text { I }\end{array}$ & $\begin{array}{r}\text { Gradus } \\
\text { II }\end{array}$ \\
\hline \multirow[t]{3}{*}{1} & Mass without calcifications & 51 & 8 & 1 & 6 & 32 & 22 \\
\hline & stellate & 40 & 4 & & 4 & 24 & 16 \\
\hline & round or oval & 11 & 4 & 1 & 2 & 8 & 6 \\
\hline \multirow[t]{4}{*}{2} & Mass with calcifications & 9 & 2 & 1 & 5 & 5 & 2 \\
\hline & powdery & 1 & & & & 1 & \\
\hline & crushed-stone like & 1 & & 1 & 1 & 1 & \\
\hline & casting & 7 & 2 & & 4 & 3 & 2 \\
\hline \multirow[t]{4}{*}{3} & Only calcifications & 12 & & & 3 & 3 & 6 \\
\hline & powdery & 3 & & & & & 3 \\
\hline & crushed-stone like & 1 & & & & 1 & \\
\hline & casting & 8 & & & 3 & 2 & 3 \\
\hline \multirow[t]{4}{*}{4} & Other & 14 & 4 & & & 8 & 10 \\
\hline & asymmetric density & 10 & 4 & & & 7 & 7 \\
\hline & architectural distortion & 4 & & & & 1 & 3 \\
\hline & Total: & 86 & 14 & 2 & 13 & 48 & 41 \\
\hline
\end{tabular}

IDC invasive ductal carcinoma, ILC invasive lobular carcinoma, ITC invasive tubular carcinoma

late mass without calcifications, which was seen in 10/28 (36\%) cancers. Casting type calcifications were seen in $7 / 28(25 \%)$ of these cancers.

Table 4 shows the distribution of mammographic findings as compared to the histological type and histological grade of 102 small breast cancers.

Invasive lobular cancers were found in $14 \%(14 / 102)$ of invasive small breast cancers and were mammographically seen as a mass or asymmetric density in 12/14 (86\%) cases. No invasive lobular cancer was mammographically seen as only calcifications.

Table 5 shows the distribution of mammographic findings as compared to histological type and histological grade of 28 small breast cancers in women under the age of 50 . There were 22/28 (79\%) grade II and III tumours in this group of young patients.

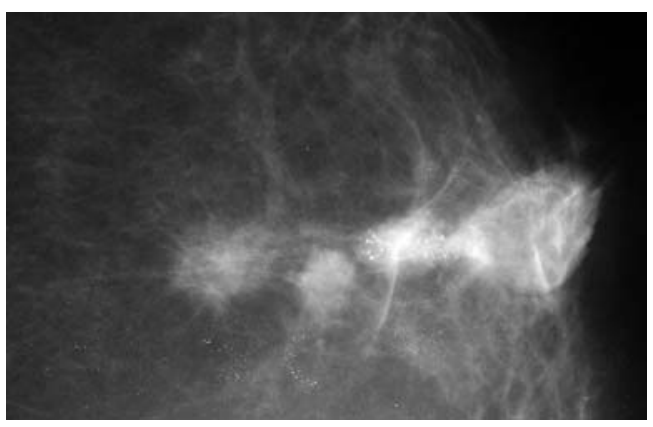

Figure 1. 48 years old women with three breast carcinomas. First stellate mass without calcifications on mammography. Histologically proven as $1 \mathrm{~cm}$ large invasive breast carcinoma, grade 2 . Second stellate mass with casting calcifications on mammography. Histologically proven as $0.9 \mathrm{~cm}$ large invasive breast carcinoma, grade 3 . Third round mass without calcifications on mammography. Histologically proven as $0.7 \mathrm{~cm}$ large invasive breast carcinoma, grade 1 .

Figure 1 shows mammographic appearance of three different synchronous cancers in a single woman. 
Table 5. The association between mammographic appearance and histological type and grade of the tumor in women under 50 years

\begin{tabular}{|c|c|c|c|c|c|c|c|}
\hline & & IDC & ILC & ITC & $\begin{array}{r}\text { Gradus } \\
11\end{array}$ & $\begin{array}{r}\text { Gradus } \\
1\end{array}$ & $\begin{array}{r}\text { Gradus } \\
111\end{array}$ \\
\hline \multirow[t]{3}{*}{1} & Mass without calcifications & 10 & 1 & & 1 & 1 & 9 \\
\hline & stellate & 9 & 1 & & 1 & 1 & 8 \\
\hline & round or oval & 1 & & & & & 1 \\
\hline \multirow[t]{4}{*}{2} & Mass with calcifications & 5 & & 1 & 1 & 3 & 2 \\
\hline & powdery & & & & & & \\
\hline & crushed-stone like & & & 1 & & & 2 \\
\hline & casting & 4 & & & 1 & 3 & \\
\hline \multirow[t]{4}{*}{3} & Only calcifications & 4 & 2 & & 3 & 1 & 2 \\
\hline & powdery & 2 & & & 1 & & 1 \\
\hline & crushed-stone like & & 1 & & & & 1 \\
\hline & casting & 2 & 1 & & 2 & 1 & \\
\hline \multirow[t]{4}{*}{4} & Other & 5 & & & 3 & 1 & 1 \\
\hline & asymmetric density & 4 & & & 2 & 1 & 1 \\
\hline & architectural distortion & 1 & & & 1 & & \\
\hline & Total: & 24 & 3 & 1 & 8 & 6 & 14 \\
\hline
\end{tabular}

IDC invasive ductal carcinoma, ILC invasive lobular carcinoma, ITC invasive tubular carcinoma

\section{Discussion}

The most common mammographic finding in small breast cancers (T1a and T1b) in our study was a stellate mass without calcifications. It was found in 44/102 (43\%) of small breast cancers. This is consistent with results of other published series. ${ }^{6-14}$ Additional 16/102 (16\%) of small breast cancers have mammographic appearance of a round/oval mass without calcifications. Calcifications with/without mass were present in 24/102 (24\%) of small breast cancers.

The important finding of our study was that the distribution of mammographic findings in small breast cancers varied with age. In the group of younger women $(<50$ years) with higher breast density, a stellate mass without calcifications was still the most common mammographic finding. It was found in 10/28 (36\%) of small breast cancers. However, the proportion of circular/oval shaped tumours was much smaller in this group of women. There was only a single woman $(1 / 28)$ with a mammographic finding of a circular/oval shaped tumour. On the other hand, calcifications with/without mass are much more common mammographic findings in younger women. In our series, $12 / 28(43 \%)$ of small breast cancers appeared mammographically as calcifications. Half $(6 / 12)$ of them with a mass and half of them without it.

More importantly, the majority of calcifications were of the casting type. Tabar ${ }^{6}$ proved by the multivariate analysis that the mammographic appearance of small breast cancers was an independent prognostic factor. In his study the mammographic appearance of casting type calcifications was more predictive of a long-term survival than clas- 


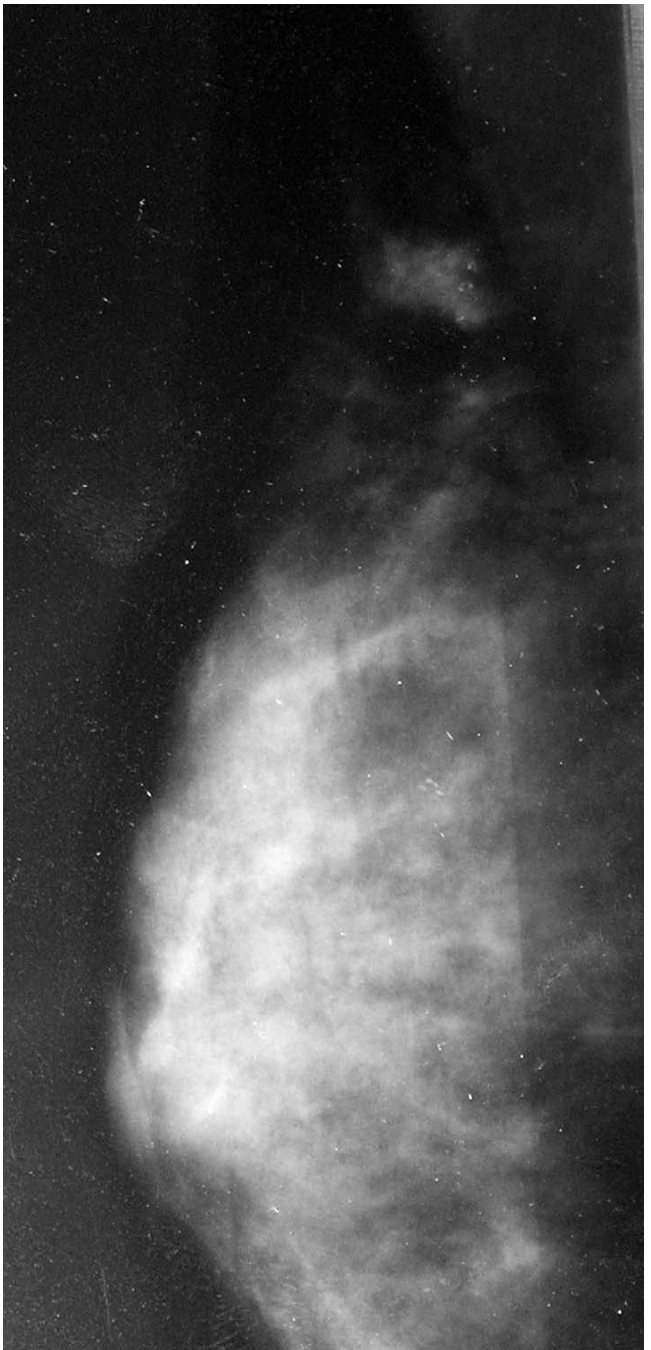

Figure 2. Mediolateral oblique view of the right breast with BIRADS category 4. Mammographic finding of $0.8 \mathrm{~cm}$ large asymmetric density. Patologically proven as invasive ductal carcinoma grade 2 .

sic prognostic factors (tumour size, histological grade and lymph node status). The 20 -year survival rate was $72 \%$ for women with small breast cancers accompanied by casting - type calcifications. All other women with small breast cancers had an excellent survival regardless of lymph node status, histological grade or treatment. ${ }^{6}$

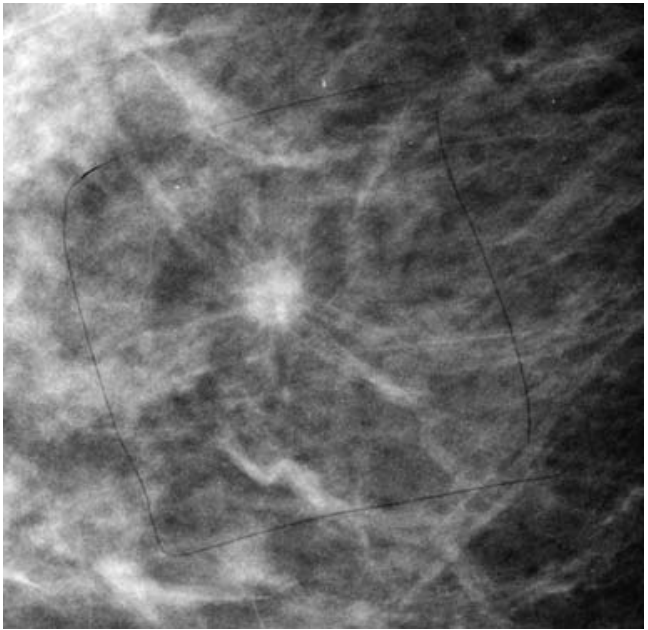

Figure 3. Stellate mass without calcifications on mammography. Histologically proven as $0.5 \mathrm{~cm}$ large invasive breast carcinoma, grade 2 .

Casting type calcifications are associated significantly with a positive lymph node status and poorer histological grade. ${ }^{6}$ In our series there were only two patients with lymph node metastases. Both of them had tumours accompanied by casting type calcifications. The majority of our patients with small breast cancers accompanied by casting type calcifications also had a higher histological grade (grade III in $7 / 15$ and grade II in 5/15).

Asymmetric breast findings define as four different types: asymmetric breast tissue, densities seen in one projections, ar-

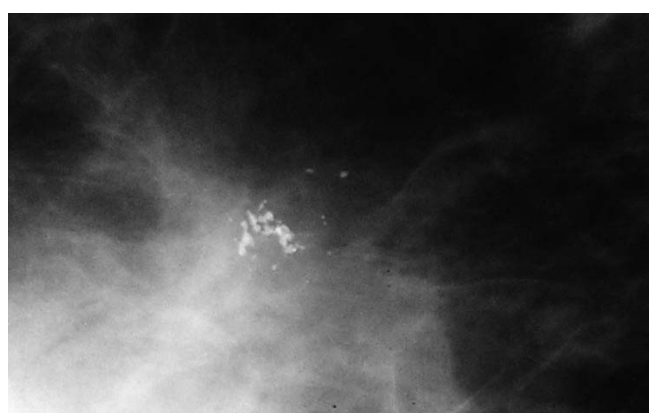

Figure 4. Crushed- stone like calcifications on mammography. Histologically $0.6 \mathrm{~cm}$ large invasive breast carcinoma, grade 1 . 


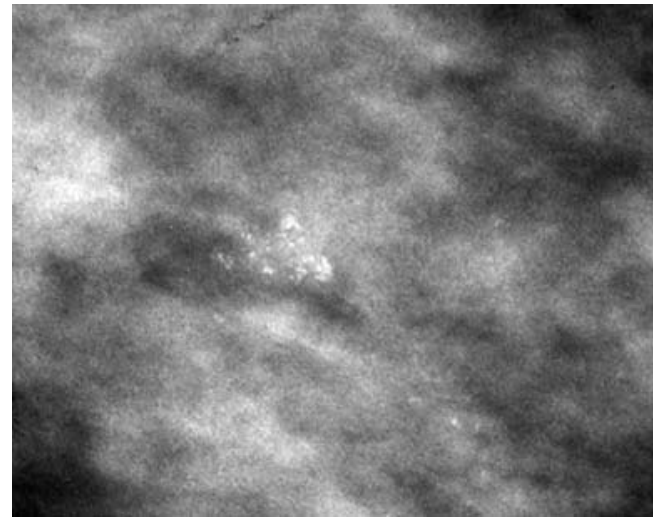

Figure 5. Powdery type of calcifications on mammography. Histologically proven as $0.4 \mathrm{~cm}$ large invasive breast cancer, gradus 1 .

chitectural distortion, and focal asymmetric densities. ${ }^{8,9}$ We have observed an architectural distortion (a focal area of breast tissue appears distorted with no definable central mass) and a focal asymmetric density also in our study. From 102 small breast cancers, $14(14 \%)$ were seen as a focal asymmetric density and 4 as an architectural distortion. Interestingly, 4/14 (26\%) of focal asymmetric density proved histologically to be invasive lobular cancers. Invasive lobular cancers accounts for $5-10 \%$ of all breast cancers and can often manifest as an area of distortion or asymmetry. ${ }^{10}$ In our series we found $14 \%$ of invasive lobular cancer, that in $86 \%$ appeared as spiculated mass or focal asymmetric density. There was no case of an invasive lobular cancer which would appear mammographically as calcifications only. This is in agreement with results of Tjurfjell. ${ }^{13}$

Samardar ${ }^{15}$ defined that palpable mass associated with a focal area of breast asymmetry or architectural distortion is very often malignant. We found in our series only 20 palpable small breast cancers and they all appeared mammographically as a mass with/without calcifications.

\section{Conclusions}

Most of the T1a and T1b breast cancers are nonpalpable. The most common mammographic finding in these cancers is stellate mass without calcifications. Calcifications are more frequent mammographic findings in younger patients. Fourteen \% of small breast cancers appear mammographically as a focal asymmetric density. Invasive lobular cancer never appears mammographically as calcifications only.

\section{References}

1. Primic Zakelj M. Cancer incidence in Slovenia 2005. Ljubljana: Institute of Oncology Ljubljana. Cancer Registry of Slovenia; 2008.

2. Fletcher SW, Elmore JG. Clinical practice. Mammographic screening for breast cancer. $N$ Engl J Med 2003; 348: 1672-80.

3. Leitch AM, Dodd GD, Costanza M, Linver M, Pressman P, McGinnis L, et al. American Cancer Society guidelines for the early detection of breast cancer: update 1997. CA Cancer J Clin 1997; 47: 1503.

4. Tabar L, Vitak B, Chen HH, Prevost TC, Duffy SW. Update of the Swedish Two-County Trial of breast cancer screening: histologic grade-specific and age-specific results. Swiss Surg 1999; 5: 199-204.

5. Barth RJ, Jr., Gibson GR, Carney PA, Mott LA, Becher RD, Poplack SP. Detection of breast cancer on screening mammography allows patients to be treated with less-toxic therapy. Am J Roentgenol 2005; 184: 324-9.

6. Tabar L, Tony Chen HH, Amy Yen MF, Tot T, Tung $\mathrm{TH}$, Chen LS, et al. Mammographic tumor features can predict long-term outcomes reliably in women with 1-14-mm invasive breast carcinoma. Cancer 2004; 101: 1745-59.

7. Rissanen TJ, Makarainen HP, Mattila SI, Karttunen AI, Kiviniemi HO, Kallioinen MJ, et al. Wire localized biopsy of breast lesions: a review of 425 cases found in screening or clinical mammography. Clin Radiol 1993; 47: 14-22.

8. Obenauer S, Hermann KP, Grabbe E. Applications and literature review of the BI-RADS classification. Eur Radiol 2005; 15: 1027-36. 
9. Kocijancic I, Rener M, Vidmar K. Simultaneous occurence of fat necrosis and carcinoma after breast injury in a traffic accident. Eur J Ultrasound 2000; 11: $213-6$.

10. Burrell HC, Pinder SE, Wilson AR, Evans AJ, Yeoman LJ, Elston CW, et al. The positive predictive value of mammographic signs: a review of 425 non-palpable breast lesions. Clin Radiol 1996; 51: 277-81.

11. Franceschi D, Crowe JP, Lie S, Duchesneau R, Zollinger R, Shenk R, et al. Not all nonpalpable breast cancers are alike. Arch Surg 1991; 126: 96770 .

12. Sickles EA. Mammographic features of 300 consecutive nonpalpable breast cancers. Am J Roentgenol 1986; 146: 661-3.

13. Thurfjell MG, Lindgren A, Thurfjell E. Nonpalpable breast cancer: mammographic appearance as predictor of histologic type. Radiology 2002; 222: 16570.

14. Tinnemans JG, Wobbes T, Holland R, Hendriks JH, Van der Sluis RF, Lubbers EJ, et al. Mammographic and histopathologic correlation of nonpalpable lesions of the breast and the reliability of frozen section diagnosis. Surg Gynecol Obstet 1987; 165: 523-9.

15. Samardar P, de Paredes ES, Grimes MM, Wilson JD. Focal asymmetric densities seen at mammography: US and pathologic correlation. Radiographics 2002; 22: 19-33. 